\title{
The Effect of Information Technology on the Recruitment Process in Healthcare Organization in Makkah City
}

\author{
Zamil Khadija ${ }^{1} \&$ Alsharqi $\mathrm{Omar}^{2}$ \\ ${ }^{1}$ Specialist Administrator, Al-Noor Specialist Hospital, Makkah, Saudi Arabia \\ ${ }^{2}$ Health Services and Hospital Administration Department, Faculty of Economics and Administration, King \\ Abdulaziz University, Jeddah, Saudi Arabia \\ Correspondence: Alsharqi Omar, Health Services and Hospital Administration Department, Faculty of Economics \\ and Administration, King Abdulaziz University, Jeddah, 21589, P O Box 80200, Saudi Arabia. Tel: \\ 966-50-466-9776. E-mail: oalsharqi@kau.edu.sa
}

Received: November 19, 2018 Accepted: January 14, 2019 Online Published: January 23, 2019

doi:10.5539/gjhs.v11n2p123 URL: https://doi.org/10.5539/gjhs.v11n2p123

\begin{abstract}
As technology advances in recruitment and selection, it provides job seekers with more options for finding a career in the healthcare industry. At the same time, it helps organizations to streamline the hiring process. Internet job sites like CareerBuilder, Monster and Hot Jobs allow job seekers to post resumes which employers can view online and select qualified candidates. In addition, online candidate-tracking systems are helpful to employers. Social media forums like Facebook and LinkedIn are useful sources when selecting proper candidates for the healthcare industry. This research set aims to analyse the role of information technology in the healthcare recruitment process. The literature review demonstrates the impact of IT on the recruitment process in the healthcare sector. Literature from different secondary sources, such as books and journals, are discussed in this research. The methodology applied in this research takes a descriptive analytical and deductive approach. In the data collection and analysis part, the data were collected from 130 human-resource employees from different healthcare organizations in Makkah city. A quantitative data analysis method has been followed in order to analyse the raw data obtained in the survey. This helps to get appropriate outcome for the research by fulfilling its research aims and objectives. The outcome results from this study were as follows: First, that using information technology will be very useful in the recruitment process, because it will provide a better outcome than traditional methods. Second, there will be improvement in the quality of recruitment when using information technology in the recruitment process. Third, there will be a small improvement in communication when IT is used in the recruitment process rather than traditional methods. Finally, using IT in the recruitment process will be much more effective than the traditional way. The recommendations made from this study are the following: As outcome is one of the major components in the healthcare industry recruitment system, the applications for providing care must not vary between institutions. In order to improve quality in the healthcare recruitment process, it is necessary to apply IT in the proper way. For instance, those applications that have security issues and may lead to data leakage of candidates must be avoided. Using social media could be useful in enhancing communication in the healthcare recruitment process. The government has an important role to play in setting up standards for organizations. In turn, following these standards could be helpful in guaranteeing the effectiveness of the system.
\end{abstract}

Keywords: information technology, recruitment, healthcare organization

\section{Introduction}

The present development of technology allows the implementation of information technology (IT) in several fields, bringing some benefits to the process as well as helping businesses secure a competitive advantage. The current study's objective is to assess the effectiveness of this, and to explore the results as well as the efficiency of information technology in the procedure of recruitment (Betancourt et al., 2016). To this end, proper methodological tools have been selected for the successful completion of the research. Appropriate and suitable research designs, research approaches and philosophies have been selected to pursue the research effectively.

IT refers to computer applications that operate in several areas to manipulate, transmit, retrieve, study and store data in a business or organizational context. IT has played a significant role in enhancing the quality, efficiency and effectiveness of communication systems and knowledge within the entire healthcare industry (Frey \& Osborne, 
2017). Due to the lower levels of IT investment in the healthcare industry than in the other service industries, however, the healthcare industry has faced several issues, such as issues with data security, enhanced data demand, patient-centered care and many other problems. One of the other major impacts of information technology is on the recruitment system process. As a result, the healthcare industry is now widely accepting the need for effective and advanced technologies to hire capable staff and enhance their service quality (Frey \& Osborne, 2017).

Virtual recruitment based on information technologies is the natural consequence of the evolution of the internet (Riggins \& Wamba, 2015). Since the core value of the internet is to share and distribute valuable information on a global scale, healthcare sectors have had a direct impact on this global influence. Healthcare sectors have encouraged their human resource departments to implement internet-based technologies to enhance the effectiveness of the recruitment process and web services to help manage the constant pressure of applicants who apply annually from various parts of the world (Fischer et al., 2014).

Human resource departments have always known the consequences of what they are getting themselves into and of their actions (Wartella et al., 2016). Therefore, it has been obvious that information technologies will play a significant role in the current technological shift. Decision makers have recognized the paradigm shift in adopting advanced technologies to move forward and have therefore invested in creative information technology solutions in order to enhance the overall recruitment process within their organizations.

We now live in a high-tech world, and so proper implementation of information technology in recruitment systems can lead to outstanding outcomes, such as fast and cost-effective recruitment. Moreover, healthcare recruitment can become more spontaneous and the length of the process reduced. In terms of quality, information technology can also have a significant impact, leading to the implementation of the most efficient recruitment system in the healthcare industry.

Furthermore, by engaging with information technology, the healthcare industry can be capable of recruiting the most competent and eligible candidates very easily (Kumar et al., 2013). Information technology plays a significant role both in implementing effective communication and in establishing proper recruitment procedures in the healthcare industry. The industry can be enriched with a large, able workforce always able to accomplish their roles and responsibilities.

The interaction between salaries and jobs has been affected by the notion that the world is flat. (Kellermann \& Jones, 2013) state that the global topography would look astonishing if we visualized a map that showed the data results of individuals with predominantly good public health. The inequity of healthcare within specific countries across the world corresponds to the lack of implementing online recruitment by healthcare sectors in these countries (Kellermann \& Jones, 2013). It has become obvious in the last five years that the medical world needs to become flatter, and that this flattening can only occur when human resources implement internet-based technologies to reshape the landscape of human health.

\section{Literature Review}

Technology has had a great impact on the hiring process in healthcare systems. There are several advantages of using information technology in the recruitment process (Sudlow et al., 2015). This section consists of different types of models and theories related to healthcare recruitment. In addition, the advantages of using IT in the recruitment process are defined here, while the impact of IT on healthcare is explained. Its limitations are also discussed.

\subsection{The Recruitment System in Healthcare Organizations}

Health information technologies (HIT) such as Decision Support Systems (DSS), Computerized Physician Order Entry (CPOE) and Electronic Medical Records (EMR), may improve wellbeing and the patient-centeredness of care and quality; however, they involve expenses and lead to incremental efficiency healthcare (Carnes et al., 2015). The use of IT equipment helps to maintain communication among employees and staff in the healthcare industry. This IT equipment includes email, social media, webcams and databases.

\subsection{Developing a Recruitment Strategy}

Efficient selection is the objective: at that point, it increases the depth of learning of the contenders for the advertised job. This implies having a reasonable vision about the position they are applying for and directing a significant portion of the hiring budget to the resources for securing practical long-term advantages for the association (Boivin et al., 2014). It is best to search for the sources of the most high-quality applicants.

In many cases, HR offices are presently forced to use up most of their energy and financial resources in overseeing their current representatives, abandoning them with little data transmission left to fill the association's procuring 
needs (George, Duran, \& Norris, 2014). The HRM department of the healthcare industry has improved and become able to maintain care services. With an excessive number of representatives, organizations can endure misfortune as the cost of maintaining the business expands in relation to income. The use of advances and new technology in HR teams has helped to support the recruitment process of the healthcare industry. Furthermore, young people in the market are given job opportunities with the help of social media (Grant et al., 2013). This has helped to increase employability in the healthcare industry. The goals and objectives of this research have been fulfilled with the help of data analysis of the collected information and data from various sources.

\subsection{Working With E-Recruiting Firms to Build a Strategy}

Using e-recruiting firms does not require the ability, time or assets to manufacture a selection procedure: unlike other alternatives, this approach involves collaborating with an enrolling firm and enabling them to deal with the procuring procedure on the organization's behalf (Parker et al., 2014). Getting the appropriate job seekers who can advance and develop the association is in many cases more vital for accomplishing the organization's general objectives than other aspects of its strategy for success. The use of this theory and model has helped in understanding the various aspects of the recruitment process in the healthcare industry. In the interviews for this research, the representatives talked about the process of administration through which everybody has particular involvement in the connective procedures through which specific issues are resolved.

In addition, the opportunity to make employment openings has to be aligned with the procedures and enhancements of situations utilized by the organization. The connections are made between staff to decide the extent of performance (Carnes et al., 2015). There is a broad selection of electronic medical records and developments in bio-therapeutic building as well as technologies. Social insurance as well as conveyance strategies are changing constantly, which expands their rate. It is important to ensure that conveyance strategies can lead to improvements and become helpful in each situation. It is important for organizations to meet the demands of users for personal satisfaction. Incentives to innovate can bring several benefits in medical services.

\subsection{Models Related to Recruitment Systems}

Diverse organizations have distinct procuring needs. Therefore, depending on the degrees of restrictiveness, long-haul prospects, levels of engagement and different variables, an assorted range of enrolment models are practiced in the market. Here we will attempt to clarify them.

Specific enrolment models can be listed as: Exclusive Requirements, Contingency Hiring, Retained Search, Outplacement, Executive Search, Recruitment, and Process Outsourcing (RPO).

\section{Exclusive Requirements}

Organizations communicate a few prerequisites just to recruitment specialists. Here, the scout guarantees to the customer that the position will be filled by a particular date. If the scout cannot fill the position by this point, he has to either fill the position with a reduced commission or incur some other penalty (Treweek et al., 2013). All the conditions are clearly set out before the agreement is made. Here, the level of commission is not as important as the possibility of employing a candidate, because there is no opposition.

\section{Contingency Hiring}

In this type of hiring, the organization will run over any prerequisites it stipulates to numerous experts; at the same time, it solicits them to send resumes. The advisor whose application is selected or finalized receives a payment from the organization. Here, the selection representatives do not receive any guaranteed or settled compensation. Their earnings depend entirely on whether they can guide or generate offers or not (Jones et al., 2016). As the hazard factor is high here, advisors charge a higher rate for this kind of enlistment. For the most part, the organization pays according to a particular level of CTC (cost to company) of the hopeful candidate. This is the most pervasive method of enrolment.

\section{Retained Search}

In this type of hiring, the recruitment expert works only for a particular recruitment instalment, separated into parts, which are often divided into two portions. He is paid a settled sum by the organization for his search. This is called a retainer fee. Other than that, on the off chance that he makes an offer then he gets more money. For the enrolment of senior administrators, like CEOs or heads of sales, an exceptionally intense approach is required, so this strategy is favoured in these cases.

\section{Outplacement}

Outplacement came into the picture amid the retreat period. Here, if an organization needs to sack a few employees 
or workers to reduce costs they may enlist a specialist to put those representatives into different organizations. The enlistment cost is paid by the current company. Outplacement is not extremely well known to date.

\section{Executive Search}

Executive searching groups just concentrate on higher-level employees like CEOs, CTOs, heads of sales and comparably sought-after staff. The plan for sourcing these mentioned positions is unique in relation to junior level necessities. The number of probable hopefuls is reduced; furthermore, they do not like to demonstrate their resume at entryways (Stephenson et al., 2014). So, head-hunting, looking in systems administration locales and individual systems, all help to a considerable degree. For such prerequisites the commission is significantly higher.

\section{Recruitment Process Outsourcing (RPO)}

RPO is beginning to show increasing prevalence recently. The resources of an organization direct the enrolment process through another expert. A few people from the expert's side operate in the organization itself and deal with the entire procedure without anyone else. These sources may either acquire the customer in place or in their own office. At this point, the RPO accomplice is in charge of securing every one of the necessities (Carnes et al., 2015). They deal with the entire enlistment process, ideally from sourcing, interviewing and scheduling to the job offer itself. The advantage to the organization is that they don't need to deal with their own enrolment group, which decreases costs.

\subsection{Recruitment and Selection Theory}

Recruiting and hiring staff needs to fulfil the human resource strategy in order to forestall the risk of terrible hiring as well as the cost of high turnover. In this aspect, private projects are not prepared for HR professionals dealing with the process of employing staff or understanding human resource speculations, or with the best practices that can enable the assembling of the ideal group for the organization (Arcade et al., 2015). On the other hand, preparation would reduce the number of requirements for terminating the employment and hence moving the representatives to several other organizations. However, this cannot be expedited legitimately.

\section{Organization Chart}

Entrepreneurs should not contract comparable individuals in dissimilar positions since they have the potential opportunity to restart employment in their previous organization. This is because business gurus typically do not begin formulating their associations with a practical organizational layout; instead, they contract workers to fill needs or loopholes as the organization progresses (Nunn et al., 2014). Viable workforce creation needs an organization diagram to determine a company's needs precisely as well as to plan for an organization's work requirements.

\section{Job Description}

To implement recruitment needs effectively, it is pivotal to conduct interviews properly and retain staff. It is important to have job descriptions for each of the positions so that the candidates are well aware of their job role and apply for the appropriate positions (Nunn et al., 2014).

\section{Recruitment}

Recruitment of staff starts with an accurate advert. The advertisement needs to include a detailed and accurate job description. Furthermore, available positions should be displayed on job boards as well as in publications that individuals with the contextual experience regularly access.

\section{Selecting}

There should be the creation of a wish list of the characteristics of the ideal employee. Resumes should be divided as per applications received. The selection should be based on the applications and assigned one point for each attribute.

\section{Hiring}

It might be discovered that the worker will not settle for the pay that the organization is offering. Pay histories do not always provide an accurate scale of a candidate's worth: it is likely that she will have enriched her aptitudes, getting better, more rewarding alternatives due to her current level of development or ability. She could have worked for a small organization, or for a massive one which could bear to compensate her more than the job offer. In the hiring process, ultimately you need to invite references from shortlisted applicants and set up direct meetings. 


\subsection{Outcome}

Some healthcare organizations have realized efficiencies through incorporating several aspects of ICT (Information and Communication Technology), such as organizational health records and picture archiving and communication systems (PACS) used for digital imaging. But for most organizations across the country, ICT is still in the rudimentary stages. Incorporating the advancement of information and communication technology within the professional arena has had a substantial influence on human resources, and together this has impacted sectors of the economy (Free et al., 2013). Those sectors which have particularly shown the influence of technology can be identified as the manufacturing and financial fields.

On the other hand, because of the several advantages of information technology the healthcare industry has started to implement it in its recruitment system. However, there is a criterion that it should be incorporated systematically rather than in a patchy and uneven way across the provinces and the whole country. In addition, provincial governments have taken initiatives by providing financial resources in integrating ventures like electronic medical records and digital and filmless imaging systems (Free et al., 2013). On the other hand, it is significant that more is being achieved as the healthcare industry embraces information and communication technology. It recognizes that the full force of the impact will be felt in the next decades (Gale et al., 2013). In this aspect, the influence of information technology on human resources in the healthcare sector needs to be considered properly.

Use of information technology has brought a massive change in the healthcare recruitment process. Boyce, Browne and Greenhalgh (2014) state that social media recruitment and application tracking systems make the process of recruitment faster and more cost-effective. The key thing to remember with social media is not to rely on it alone. One needs to create a binding relationship with potential clients. However, social media helps to make communication easier and faster with the candidates in the recruitment process. In addition, social media helps to find candidates from different countries. Application tracking can be the most useful tool, and it has had a technological impact on the recruitment system. It is a great tool for scanning resumes and finding matches. It speeds up the process and makes it much easier.

\subsection{Quality}

It is important for a healthcare organization to provide a quality care service for service users. From a human-resources viewpoint, some implications of the technology can be listed as follows (Gale et al., 2013). There will be a growing need for medical informatics specialists with experience of the medical field, and vice versa. These must be properly trained, as they will encounter the complicated ICT requirements of healthcare organizations.

The composition of healthcare teams will change as information and communication technology acts as an important role player and is considered as increasingly important in medical care. Smaller systems for organizations need to provide a smaller number of physicians who will be capable of overseeing the care of larger numbers of patients and procedures (Gale et al., 2013). A smaller number of physicians would be capable of supporting the system. Currently, some experts assume that medical care has become increasingly reliant on technology.

\subsection{Communication}

IT helps to develop clear, consistent and timely procedures for communicating with applicants and for hiring the right employees in the healthcare recruitment process. Documentation of the procedures and decision-making stages in the recruitment process requires written or verbal communication. Use of information technology makes this communication faster and easier through social media sites and other communication mediums like email. At the same time, automated communication helps to preserve records and emails as the applicants are moved through distinct stages in the recruitment procedure. Tracking all communication makes an application tracking system highly valuable (Bower et al., 2014). In addition, effective communication with the applicants helps to keeping hiring managers as well as other employees informed regarding the status of open positions. It protects the organizations against false accusations or legal repercussions if candidates misinterpret communications. Hence, the use of IT is helpful to develop effective communication with the candidates in the recruitment process.

There are several ways through which communication in healthcare services can be improved upon, explained as follows:

\section{Social Media Recruiting}

Even though social media recruitment is not considered as something new, either in content or style, there are a couple of social media approaches that have become better known since 2014 and did precede it. One incorporates 
virtual meetings through video, as well as involving a web-based networking profile maintained on social media, which is a major facet of the job application when compared with the manual approach to screening the applicants for recruitment. This may be the most significant approach to using online networking, which in turn serves as a referral source to judge the candidate (Carnes et al., 2015). As many as $30 \%$ of organizations and more have seen a recognizable growth in their referral applicants, once hired through social registering. Referral hopefuls are observed to be the ones who have low job turnover and who remain with the organization for a long time, fulfilling the responsibilities of their position in the most professional manner.

On the other hand, the enormous trap with online networking is failing to identify customers; an organization has to make sure that it has an association with potential customers (Boyce, Browne \& Greenhalgh 2014). Online networking does not mean not conversing with hopefuls, or that web-based social networking selection is free: this is because the stages can utilize a lot of resources. Social enrolling has its own arrangement of best practices, much like the enlisting procedure itself.

\section{Application Tracking Systems}

Application Tracking Systems make up one of the most accommodating technologies in the sector. Selection representatives and contracting supervisors often state that it is an extraordinary instrument for checking resumes as well as finding matches. In view of this, an ATS (Application Tracking System) can be best used through application of a well-prepared contractor's eye along with relevant innovation.

\section{Mobile Recruiting}

More than $60 \%$ of recruiters stated that mobile recruitment was considered the best pattern for 2014 . At any rate, the occupation page should be enhanced to demonstrate the versatile capability to perform a task through experience. This enables recruiters to identify latent competitors much more effortlessly. Equally, in the event that it is done well, it provides an excellent snapshot of the candidate. $61 \%$ of individuals present said that they had a greater perception of the brand when considering the developing versatile experience outlook (Rivers et al., 2013). In the past, the profession page as well as the page of managers had to consider improving different parts of the resourceful client encounter. This would combine to create a multipurpose benevolent application process and augmenting heap times in contrast to reasonable prospects. The components decrease the number of prospective challengers in cases where they are not quick and user friendly.

\section{Job Boards and Career Pages}

This specific part of selection as well as the implications of technology are not considered in their latest form. The calculations for the sheets of employment are more than 15 years old, as are the professions pages. These are acceptable for setting up the sites. On the other hand, technology has proved that the new system will supersede employment sheets and vocation pages. These are the changing processes of using the enlisting devices (De Silva et al., 2014). Several enrolling methods direct users to the profession pages as well as the positions that are posted by the working manager. Online network sharing of messages can be received through portable platforms.

\section{Developing Effective Communication}

It has been considered that there are a wide range of ICTs, which are computerized gadgets used by attendants as a route for providing medical services. These separate e-health portals (i.e., the utilization of developing data and communication technology, particularly the internet, to enhance or empower health and human services) into four areas: management systems, communication systems, computerized decision support systems and information systems. Each of them will be clarified as follows:

\section{Management Systems}

Management Systems are PC-based frameworks for procuring, securing, transmitting and displaying managerial or health information from various sources, which can support regulatory or clinical exercises. Management systems incorporate ICTs, for example electronic health records and individual (patients) health records.

\section{Communication Systems}

Communication Systems are media telecommunication systems utilized when clients are far away geographically as well as in time. This sort of communication happens in a synchronous or non-concurrent path, between health experts or between health experts and patients (Carnes et al., 2015). It includes a focused-on sharing of data between particular people, or between people who assume unmistakable parts for demonstrative, administrative, advising, instructive, or bolster purposes. There is an extensive variety of correspondence frameworks, from email and advanced mobile phones through to tele-medicine and tele-care systems. 


\section{Computerized Decision Support Systems}

These systems allude to a PC-based framework which is mechanized and intended to help health experts rehearse inside clinical rules and healthcare pathways, or to give best proof of care. These sorts of frameworks are normally operated continuously and include choices to help that originate from computerized reasoning.

\section{Information Systems}

These systems are characterized by the utilization of web-based innovation to achieve access to various data assets, for example, health and way-of-life data. The data stay at a general level and are not customized to individual needs. Online assets and e-health entries for recovering data are utilizations of data systems.

\subsection{Effectiveness}

In the present day, there is a global competent workforce crisis, which is based on irregular characteristics. Several states are facing the dilemma of a lack of medical caretakers, specialists, dental specialists, physiotherapists, drug specialists and other capable workers. Concurrently, for quite a few countries these deficiencies co-exist with jobless and under-employed wellbeing experts because of financing deficiencies, geographical obstacles and arrangement insufficiencies between the supply of wellbeing suppliers and the concerns of their supervisors (Gast $\&$ Ledford 2014). The causes of the emergency are thus diverse and multifaceted, yet the pivotal reasons they share are underprivileged workplaces and the poorly managed administrative atmosphere that evidences numerous working hindrances.

The ongoing under-investment crisis in the wellbeing and health industry, combined with unsatisfactory business arrangements and conditions (for example, inadequate compensation; troublesome work-life balance; unrealistic workloads; restricted vocation advancement openings), have initiated a disintegration of working conditions for wellbeing experts in several nations. There is strong evidence that this has had a direct negative consequence on the maintenance and enrolment of health experts. Considering the operation and efficiency of wellbeing offices helps in understanding results (Gale et al., 2013). Effective recruitment with the help of IT systems can be helpful to the organization in gaining competitive advantage to offset these problems.

\subsection{Impact of IT on Healthcare Recruitment}

Technology is not considered as merely something that every individual relies upon to complete mundane tasks and to remain connected. Rather, it also influences the processes by which businesses select staff of good ability and excellent managers (Gale et al., 2013). Several recruiting designs were applied in the 2014 project that either invested in new technology, which would ultimately affect selection, or would present technology registering styles that will persist as a genuine nightmare in the upcoming year.

\subsection{Challenges for Implementing IT in Healthcare Recruitment}

Acquiring and implementing information technology can be challenging in the healthcare recruitment process. Organizations face difficulties in applying IT in the recruitment process. On the other hand, managing change is different from training. Thus, additional support needs to be available after providing training to help managers clearly explain the process to employees in order to discuss changes. Evaluating the quality as well as the accuracy of information is vital for using IT in the healthcare recruitment process. Those organizations that adopt IT for the first time in their recruitment process face a challenge to maintain the quality and accuracy of the information it provides. In addition, the cost issue is one of the major challenges for implementing IT in the healthcare recruitment process. Technology can likewise bring concealed perils if people are not careful. Information on websites is known for this. However, it can divert an endless stream of useful information that can be accessible online. It is important to note that WebMD is an asset to be used properly (Gast \& Ledford 2014). There are some cases where technology can manipulate results. It is important to select the most effective processes by choosing the most suitable technology for them. At the same time, complying with legal requirements is a major challenge for healthcare organizations wishing to implement IT in the recruitment process.

It can be summarized that IT has an important role to play in the recruitment system of an organization. Healthcare services, as an industry, is almost the absolute opposite of enlisting: as healthcare professionals are naturally held in high regard and innately trusted, while their ability or judgment goes unchallenged. We put our lives in their grasp. On the other hand, IT has an important role to play in the overall recruitment system in healthcare that is explained in the research.

\section{Research Problem}

IT has the potential to solve the problem of an organization's everyday practice, which is spending excessive time and effort in analysing each applicant. However, the conventional human resource management system within the 
healthcare industry has proven to be time-consuming and less effective (Or \& Tao, 2014). Information technology offers a high-level design solution to help human resources enhance and increase the performance of the recruitment process. Based on the above information, this study will investigate the effect of information technology on the recruitment process in healthcare organizations. Information technology is heavily impacting human resource management systems as well as recruitment processes within healthcare centers in the modern digital world (Kumar et al., 2013). The healthcare recruitment process mainly adopts a positive process to search for prospective employees and encourages them to apply for jobs in the healthcare industry (Smith, 2015).

\section{Research Importance}

The major areas of importance in this research are:

- The most powerful outcome of online recruitment is that it enables more applicants to apply; therefore, it can reach potentially more sophisticated users, ensuring that it reaches a wider demographic. This acquisition cannot be done in a traditional way.

- Online recruitment and other digital platforms can stand as a business-matching platform when it is implemented by human resources, which can ultimately enhance the quality of the healthcare industry's operations.

- In order to implement an efficient recruitment system within the healthcare industry, effective communication must be established between the candidates and the HR department of the organization. IT implementation can simply enhance the scope of effective communication within the healthcare industry.

- The traditional recruitment system within the healthcare industry is time-consuming and less effective. Information technology is playing a crucial role in enhancing effectiveness and reducing the problem of time-consumption (Or \&Tao, 2014).

\section{Research Objectives}

The objectives of this research are:

- To explore the outcomes of information technology for the recruitment process in the healthcare industry

- To evaluate the quality of information technology in the recruitment process of the healthcare industry

- To evaluate the impact of information technology on building effective communication systems within the recruitment processes of the healthcare industry.

- To evaluate the effectiveness of information technology in the recruitment processes of the healthcare industry.

\section{Research Variables and Hypotheses}

Independent Variable: The independent variable of this study is the effect of information technology that contains the following axes: outcome, quality, communication and effectiveness.

Dependent Variable: The dependent variable of this study is the recruitment process in the human resource department in the healthcare organization.

The hypotheses for this research are as follows:

- There is a significant statistical relationship between the outcomes of information technology and the recruitment process in human resource departments in the healthcare industry.

- There is a significant statistical relationship between the quality of information technology and the recruitment process in human resource departments in the healthcare industry.

- There is a significant statistical relationship between effective communication using information technology and the recruitment process in human resource departments in the healthcare industry.

- There is a significant statistical relationship between the effectiveness of information technology and the recruitment process in human resource departments in the healthcare industry.

\section{Methodology}

The research methodology assists in defining the most appropriate approach necessary to be adopted for attaining details about the procedure and all of its outcomes (Arcade et al., 2015). Specific theories and concepts are adopted in the research methodology that can help improve the research analysis. In addition, the research methodology helps to understand the process adopted in analysing the role of IT in the recruitment system of healthcare 
organizations.

\subsection{Research Philosophy}

In research methodology, the application of a research philosophy assists in determining the best way to obtain details of the research topic (Choy, 2014). The research philosophy helps to describe the procedure governing the assumptions made by the researcher at the time of conducting the research (Bonevski et al., 2014). Equally, the procedure of assessing the research topic can be varied when selecting the research philosophy that is both effective and appropriately aligned.

A descriptive research philosophy refers to those circumstances that are present in a context in which the researcher has no control, or which is variable. In addition, descriptive research can be characterized as determining or identifying the analytical research.

In the present research context, a descriptive research philosophy has been applied in order to cast light on present issues by the procedure of data collection. It also enables us to explain the particular situation without implementing the method. This particular philosophy has been adopted because it is associated with the impact of adopting information technology into the healthcare recruitment system (Flick, 2015). Apart from this, the nature of the study has time limitations. Thus, the choice of a positivism philosophy allows the researcher to focus in order to manipulate and assess the data, leading to reduction of data errors.

\subsection{Research Approach}

The research approach is important for the research so that the format in which it is conducted can be revealed (Gale et al., 2013). The research topic could have been undertaken for the present study in two ways, inductive and deductive but, as noted above, it used a deductive approach. That is, it utilized as procedure which explains the practical application of theories to access the content of the research (Gast et al., 2014). In this topic we try to analyse the role of information technology in the healthcare recruitment system theoretically. Thus, choosing a deductive approach is most helpful to the present research.

\subsection{Research Design}

Research design assists in describing the framework of the research topic. It assists in the collection of data as well as in pattern analysis (Humphries, 2017). During the data collection procedure, a specific type of research approach has been applied which helps explain the research topic better (Wiek \& Lang, 2016). The type of research design utilized in the academic research pattern is explanatory as well as descriptive. Descriptive design is helpful in defining the detailed procedure used in the application of IT in healthcare recruitment systems.

\subsection{Data Collection Process}

Mackey and Gass (2015) have defined the data collection method as the process of measuring and collecting data on the targeted variables in a systematic way. Moreover, the data collection method can also help an individual answer relevant questions relating to specific research and evaluate outcomes of their search. The data collection method mostly depends on the nature of the investigation and the questions to be investigated. The data collection method can be sub-divided into two methods, the primary and secondary data collection methods.

In this study we use the primary data collection method: this research technique is carried out by asking a few questions or raising issues associated with the research. Primary data collection can be carried out by conducting surveys, interviews or questionnaires with a small group of individuals.

The primary data were gathered by conducting surveys among 130 employees from six healthcare organizations. The tools relating to the secondary sources consist of online as well as offline sources, such as articles, books, websites and blogs.

\subsection{Data Analysis Technique}

According to Smith (2015), data analysis is the method or technique of modeling, transforming, cleansing and inspecting data with the objective of discovering helpful details, supporting decision-making and suggesting conclusions. The data analysis technique can be categorized into two subdivisions, qualitative and quantitative. According to Riggins and Wamba (2015), quantitative data analysis is referred to as a systematic approach to investigations, where numerical data is gathered and the researcher transforms what is observed or collected into numerical data. Standard deviation is used as a measure of dispersion variation in the process of distribution that is equal to the square root of the arithmetic mean of squares of deviations from the arithmetic mean.

Hence, in this research, a quantitative data analysis technique was utilized to analyse the numerical data collected from the survey conducted among 130 employees of the six organizations within the healthcare industry (Mackey 
\& Gass, 2015). In this context, the questionnaire data were electronically stored in a spreadsheet-like table and from which were generated routine descriptive statistical data responding to the questions, like frequency counts of the close-ended questions and distribution of multiple-choice response questions. The statistical analysis used in this study are mean, stander deviation, multiple regressing test and chi squared.

\subsection{Population and Sample}

Mackey and Gass (2015) have defined population as the process of bringing all people or items together with a single characteristic goal: of understanding. In addition, the goal becomes finding a representative sample of that population, as there is very rarely enough time or money to gather information from everything or everyone within a population. In the present study, human resource employees were taken as a sample as they are involved directly with the process of recruitment.

As per the sampling technique, Dranove et al. (2014) state that several sampling methods can be individually combined or employed within any of the types of frames, such as probability sampling and non-probability sampling. There are a few factors that commonly influence the selection between several designs, such as frame quality and nature, operational or cost concerns and accuracy requirements. As the recruitment process is directly involved with the activities of human resource managers in the organization it is necessary to take the opinions of the managers into account in order to determine the best possible method for recruitment. In addition, in this study the sampling process required surveying six hospitals in Makkah.

Hence, in this research, a probability sampling technique has been utilized by the researcher to analyse the primary data collected from a survey. At the same time, it must be specified that in order to collect the primary data, a survey of 130 human resource employees from several healthcare organizations were conducted in this research so as to reach a proper finding for this study. After collecting the data, a quantitative analysis could be performed.

Table 1. Study Sample

\begin{tabular}{clc}
\hline No & Hospital name & No of employee \\
\hline $\mathbf{1}$ & King Faisal hospital & 27 \\
$\mathbf{2}$ & King Abdullah hospital & 27 \\
$\mathbf{3}$ & Obstetrics hospital & 15 \\
$\mathbf{4}$ & Al Noor hospital & 20 \\
$\mathbf{5}$ & King Abdul Aziz hospital & 21 \\
$\mathbf{6}$ & Hera Hospital & 20 \\
\hline Total & & 130 \\
\hline
\end{tabular}

\subsection{Validity}

Sampling is considered to be a good way to study the role of IT in recruitment systems in healthcare organizations (Smith, 2015). The sample of employees of healthcare organizations involved a simple random probability sampling in which no criteria for selection were considered (Vaioleti, 2016). With the help of the questionnaire, HR managers were asked to participate; the survey was then performed based on a Likert scale rating (strongly agree, agree, neither, disagree, strongly disagree). In order to study the quantitative research results, 130 employees of healthcare organizations were considered and asked to respond with the assistance of the questionnaire. Thus, the total sample size was 130 in the research. 
Table 2. The Validity of the Questionnaire

\begin{tabular}{|c|c|c|c|c|c|}
\hline No & $\begin{array}{l}\text { The outcome of using } \\
\text { IT for recruitment in } \\
\text { the healthcare } \\
\text { organization }\end{array}$ & $\begin{array}{l}\text { The quality of using } \\
\text { IT for recruitment in } \\
\text { the healthcare } \\
\text { organization }\end{array}$ & $\begin{array}{l}\text { The effect of using IT } \\
\text { for recruitment in } \\
\text { communication in the } \\
\text { healthcare organization }\end{array}$ & $\begin{array}{l}\text { The effectiveness of } \\
\text { using IT for } \\
\text { recruitment in the } \\
\text { healthcare } \\
\text { organization }\end{array}$ & $\begin{array}{l}\text { The recruitment } \\
\text { process in the } \\
\text { healthcare } \\
\text { organization }\end{array}$ \\
\hline 1 & $0.785^{* *}$ & $0.879 * *$ & $0.875^{* *}$ & $0.789 * *$ & $0.888^{* *}$ \\
\hline 2 & $0.850 * *$ & $0.921 * *$ & $0.799 * *$ & $0.905 * *$ & $0.760 * *$ \\
\hline 3 & $0.798 * *$ & $0.831 * *$ & $0.803 * *$ & $0.788 * *$ & $0.756^{* *}$ \\
\hline 4 & $0.755^{* *}$ & $0.877 * *$ & $0.911^{* *}$ & $0.861 * *$ & $0.911 * *$ \\
\hline 5 & $0.777 * *$ & $0.931 * *$ & $0.937 * *$ & $0.810^{* *}$ & $0.900^{* *}$ \\
\hline
\end{tabular}

Table 2 shows that is all correlation confidents were significant where they ranged from 0.755 to 0.850 in the outcome of using IT on recruitment in the healthcare organization; 0.831 to 0.931 for the quality of using IT on recruitment in the healthcare organization; 0.799 to 0.937 for the effect of using IT on communication in recruitment in the healthcare organization; 0.756 to 0.911 for the effectiveness of IT on recruitment in the healthcare organization; and from 0.788 to 0.905 for the recruitment process in the healthcare organization. These values prove the items to be valid.

\subsection{Reliability}

Reliability is the degree to which an assessment tool generates stable as well as continuous results (Tarone et al., 2013). Cronbach's alpha is considered to be one of the most generally accepted measures of internal consistency. It is commonly used when multiple Likert questions in a survey form a scale and when researchers wish to determine whether the scale is reliable. In the SPSS statistics, a set of questions were labeled throughout the process. In order to understand them correctly, the data were entered into SPSS statistics for running a Cronbach's alpha test. Alpha measures which item responses are gained at the same time and which correlate to the process with each other to the highest extent. The rules can be applied when getting more items and placing them more reliably on a scale.

Table 3. The Reliability of the Questionnaire

\begin{tabular}{|c|c|c|c|c|c|c|}
\hline \multirow{2}{*}{ Statement } & \multicolumn{2}{|c|}{ First Round } & \multirow{2}{*}{ P-Value } & \multicolumn{2}{|c|}{ Second Round } & \multirow{2}{*}{ P-Value } \\
\hline & Mean & SD & & Mean & SD & \\
\hline $\begin{array}{l}\text { The outcome of using IT on recruitment in the } \\
\text { healthcare organization }\end{array}$ & 18.900 & 4.748 & 0.850 & 18.700 & 4.165 & 0.855 \\
\hline $\begin{array}{l}\text { The quality of using IT on recruitment in the } \\
\text { healthcare organization }\end{array}$ & 15.300 & 4.084 & 0.820 & 16.800 & 5.613 & 0.821 \\
\hline $\begin{array}{l}\text { The effect of using IT in recruitment on } \\
\text { communication in the healthcare organization }\end{array}$ & 16.600 & 3.273 & 0.900 & 19.100 & 5.915 & 0.901 \\
\hline $\begin{array}{l}\text { The effectiveness of using IT on recruitment in } \\
\text { the healthcare organization }\end{array}$ & 16.100 & 5.507 & 0.885 & 20.200 & 4.417 & 0.890 \\
\hline $\begin{array}{l}\text { The recruitment process in the healthcare } \\
\text { organization }\end{array}$ & 16.200 & 4.367 & 0.822 & 20.700 & 3.268 & 0.823 \\
\hline
\end{tabular}

Table 3 shows the P. value reliability of the questionnaire, which range from 0.820 to 0.900 for the first round and from 0.821 to 0.901 for the second round for all domains; and these values prove that the sample was reliable so that we could study it.

\section{Results and Discussion}

In this part, the researcher attempts to demonstrate in the data analysis the impact of IT on the healthcare recruitment process. With the assistance of quantitative analysis, the process of data analysis enables the researcher to develop the nature of the data and improve the examination of the decision-making relating to a specific point. Data analysis helps a researcher to deploy theoretical knowledge in practical application.

Data analysis consists of complexities as well as confinements (Frey \& Osborne, 2017). For example, controlling 
information and the absence of validity are included in this. Data analysis is one of the processes that helps people. In this manner, a crosscheck procedure is watched by means of information investigation in an examination. A part of marking-in clients' basic leadership processes is assessed in this section with the assistance of inputs given by the respondents in connection to the different healthcare organizations. According to the information selected in this part, the researcher endeavors to select the data identified with the theme and where necessary apply the discoveries to advertisement legitimacy according to time spent as well as data accumulations. The respondents are considered for the process of data collecting as well as specific and detailed information extricated from the research work.

Table 4. Distribution of Data in Study Group ( $\mathrm{n}=130)$

\begin{tabular}{|c|c|c|}
\hline Categories & $\mathbf{N}$ & $\%$ \\
\hline \multicolumn{3}{|l|}{ Hospital } \\
\hline Al -Zaher Hospital & 21 & 16.2 \\
\hline Hira Hospital & 19 & 14.6 \\
\hline Al -Nour Hospital & 20 & 15.4 \\
\hline King Faisal Hospital & 27 & 20.8 \\
\hline King Abdullah Hospital & 16 & 12.3 \\
\hline Maternity and child hospital & 27 & 20.8 \\
\hline \multicolumn{3}{|l|}{ Jobs } \\
\hline Head & 6 & 4.6 \\
\hline Supervisor & 12 & 9.2 \\
\hline Employee & 112 & 86.2 \\
\hline \multicolumn{3}{|l|}{ Age } \\
\hline$<\mathbf{3 0}$ & 22 & 16.9 \\
\hline $30-40$ & 66 & 50.8 \\
\hline $40-50$ & 23 & 17.7 \\
\hline $50-60$ & 19 & 14.6 \\
\hline
\end{tabular}

This table shows the frequency distribution of the study group and reveals that approximately less than one fifth were from Al-Zaher hospital, with a percentage of $16.2 \%$; approximately the same percentage were from Al- Nour hospital, with a percentage of $15.4 \%$; more than one fifth were from King Faisal hospital, with a percentage of $20.8 \%$, and the same from the Maternity and Child hospital, with a percentage of $20.8 \%$; while less than one fifth were from King Abdullah hospital, with a percentage of $12.3 \%$. As regards Jobs, the highest percentage (86.2\%) of the sample were employees, the lowest percentage (4.6\%) were heads, and $9.2 \%$ were supervisors. The data reveal that just over half the sample (50.8\%) were 30 to 40 years of age.

Table 5. The Impact of Outcome on Recruitment in the Healthcare Organizations $(\mathrm{n}=130)$

\begin{tabular}{lllllll}
\hline \multirow{2}{*}{ No } & Statement & Mean & SD & \multicolumn{2}{c}{ Chi-Square } \\
\cline { 3 - 6 } & & $\mathbf{X}^{\mathbf{2}}$ & DF & P-value \\
\hline $\mathbf{1}$ & Use of IT can bring transparency to the healthcare recruitment system & 4.492 & 0.718 & 110.308 & 3 & 0.000 \\
\hline $\mathbf{2 2}$ & $\begin{array}{l}\text { Use of IT platforms like social media in the recruitment selection } \\
\text { procedure may hamper data privacy of an individual }\end{array}$ & 3.569 & 1.154 & 40.000 & 4 & 0.000 \\
\hline $\mathbf{3}$ & Use of IT would be helpful in screening and shortlisting employees & 3.985 & 0.932 & 29.077 & 3 & 0.000 \\
\hline $\mathbf{4 4}$ & Social network assists in the selection of the right employees & 4.077 & 0.937 & 88.231 & 4 & 0.000 \\
\hline $\mathbf{5}$ & $\begin{array}{l}\text { IT platforms are helpful to the overall recruitment procedure in the } \\
\text { healthcare organization }\end{array}$ & 4.123 & 0.940 & 91.231 & 4 & 0.000 \\
\hline \multicolumn{2}{l}{ Total } & & 4.05 & 3.22 & &
\end{tabular}

*significant at P-value less than 0.05 . 
Table 5 shows that all of the outcomes of using IT for recruitment categories in healthcare organizations were significant, where the p-value for each item was less than 0.05 and the total mean was 20.25 by SD 3.22.

$>$ In this table, point no (1) gets the highest value of Mean \pm SD (4.492 \pm 0.718$)$.

$>$ And point no (2) gets the lowest value with Mean \pm SD (3.569 \pm 1.154$)$.

The data presented in Table 5 clearly show that the mean value generated for using IT can bring transparency to the healthcare system, whereas the role of social media generates a mean value of 3.569. On the other hand, a previous study relating to the effectiveness of applying information technology in the healthcare system indicates that the security issue is a major concern (Cresswell \& Sheikh, 2013). The result is a contrast between the two studies. However, statistical analysis proves that a greater number of respondents think that adopting IT can be helpful for organizations to bring effectiveness into the system.

Table 6. The Impact of Quality on Recruitment in the Healthcare Organization ( $\mathrm{n}=130)$

\begin{tabular}{|c|c|c|c|c|c|c|}
\hline \multirow[t]{2}{*}{ No } & \multirow{2}{*}{ Statement } & \multirow{2}{*}{ Mean } & \multirow{2}{*}{ SD } & \multicolumn{3}{|c|}{ Chi-square } \\
\hline & & & & $\mathrm{X}^{2}$ & DF & P-value \\
\hline 1 & The present recruitment process in your organization is of sufficient quality & 3.762 & 1.167 & 42.231 & 4 & 0.000 \\
\hline 2 & $\begin{array}{l}\text { IT platforms bring more opportunity as well as diversity to the } \\
\text { organizations for selecting qualified employees }\end{array}$ & 3.962 & 0.918 & 95.923 & 4 & 0.000 \\
\hline 3 & $\begin{array}{l}\text { Using IT in the healthcare recruitment system allows you to meet the } \\
\text { current needs of your organization in maintaining quality }\end{array}$ & 3.977 & 0.992 & 71.077 & 4 & 0.000 \\
\hline 4 & $\begin{array}{l}\text { Healthcare staff need to be technically advanced along with having core } \\
\text { expertise to provide quality care in the healthcare system }\end{array}$ & 4.054 & 0.959 & 91.462 & 4 & 0.000 \\
\hline 5 & $\begin{array}{l}\text { Transparency in the recruitment system with the help of IT can be helpful in } \\
\text { providing quality care to service users }\end{array}$ & 4.092 & 0.935 & 98.385 & 4 & 0.000 \\
\hline \multicolumn{2}{|c|}{ Total } & 3.97 & 3.59 & & & \\
\hline
\end{tabular}

*significant at P-value less than 0.05 .

Table 6 shows that overall the impact on quality of using IT for recruitment in healthcare organization items was significant, where the p-value for each item was less than 0.05 and the total mean was 19.85 by $\operatorname{SD}(3.59)$.

$>$ Also, in this table point no (5) gets the highest value, with Mean \pm SD (4.092 \pm 0.935$)$.

$>$ And point no (1) gets the lowest value, with Mean \pm SD (3.762 \pm 1.167$)$.

The Percentage of Agreement Regarding Quality table indicates that the mean value of meeting quality needs with the present recruitment system is 3.762 , whereas the SD value is 1.167 . In contrast, regarding the question of IT platforms providing more scope and diversity for the selection of qualified staff, participants responded with a 3.962 mean value and a $0.918 \mathrm{SD}$ value. The previous study implicating m-health clearly shows its effectiveness and capacity to meet quality needs in the organizations (Close et al., 2013). Hence, the total mean value (19.85) and SD value (3.59) support the statement that deploying IT in the healthcare recruitment system will meeting quality requirements. 
Table 7. The Impact of Communication on Recruitment in the Healthcare Organization $(\mathrm{n}=130)$

\begin{tabular}{|c|c|c|c|c|c|c|}
\hline \multirow{2}{*}{ NO } & \multirow{2}{*}{ Statement } & \multirow{2}{*}{ Mean } & \multirow{2}{*}{ SD } & \multicolumn{3}{|c|}{ Chi-square } \\
\hline & & & & $X^{2}$ & DF & P-value \\
\hline 1 & $\begin{array}{l}\text { Social media has an important role to play in improving communication } \\
\text { in the healthcare recruitment system }\end{array}$ & 3.977 & 1.074 & 70.000 & 4 & 0.000 \\
\hline 2 & $\begin{array}{l}\text { Email, social media and other electronic mediums are more effective than } \\
\text { traditional communication systems in the organization }\end{array}$ & 4.169 & 0.949 & 102.846 & 4 & 0.000 \\
\hline 3 & Use of IT mediums can lead to security issues in communication systems & 4.108 & 0.847 & 107.000 & 4 & 0.000 \\
\hline 4 & $\begin{array}{l}\text { Use of IT is more expensive than traditional systems used in healthcare } \\
\text { organizations }\end{array}$ & 3.585 & 1.206 & 26.154 & 4 & 0.000 \\
\hline 5 & $\begin{array}{l}\text { Use of IT platforms and applications will be the only method in the future } \\
\text { recruitment process }\end{array}$ & 4.062 & 0.971 & 90.692 & 4 & 0.000 \\
\hline Total & & 3.98 & 3.45 & & & \\
\hline
\end{tabular}

*significant at P-value less than 0.05 .

Table 7 shows that all of the effects of using IT in recruitment in healthcare on communication items were significant, where the p-value for each item was less than 0.05 and the total mean was 19.90 by SD (3.45).

$>$ In this table, point no (2) gets the highest value with Mean \pm SD (4.169 \pm 0.494$)$.

$>$ And point no (4) gets the lowest value with Mean \pm SD (3.585 \pm 1.206$)$.

The table showing the percentages of agreement regarding communication shows that the total mean value is 19.90 and the SD value is 3.45. This proves that social media has a significant role to play in improving communication in the healthcare recruitment system by implementing information technology in the recruitment system. A previous study examining improvement of communication by implementing IT produced results that suggested increased effectiveness in communication (Turan \& Palvia, 2014). This is in line with our results.

Table 8. The Impact of Effectiveness on Recruitment in the Healthcare Organization in the Study Group ( $\mathrm{n}=130)$

\begin{tabular}{lllllll}
\hline \multirow{2}{*}{$\mathbf{N o}$} & Statement & Mean & SD & \multicolumn{3}{c}{ Chi-square } \\
\cline { 4 - 6 } $\mathbf{1}$ & $\begin{array}{l}\text { Use of IT has an important role to play in improving effectiveness in the } \\
\text { recruitment system }\end{array}$ & 4.000 & 0.932 & 97.538 & 4 & 0.000 \\
\hline $\mathbf{2}$ & $\begin{array}{l}\text { Your organization needs to focus on using IT in the recruitment process in } \\
\text { order to increase the effectiveness of the system }\end{array}$ & 4.015 & 0.940 & 83.077 & 4 & 0.000 \\
\hline $\mathbf{3}$ & $\begin{array}{l}\text { Technically advanced people can be able to provide an effective } \\
\text { healthcare system }\end{array}$ & 3.992 & 0.902 & 47.046 & 3 & 0.000 \\
\hline $\mathbf{4}$ & $\begin{array}{l}\text { Social media can bring effectiveness to the communication system in the } \\
\text { healthcare organization }\end{array}$ & 4.031 & 0.988 & 93.538 & 4 & 0.000 \\
\hline $\mathbf{5}$ & $\begin{array}{l}\text { Use of IT platforms affects the effectiveness of medical staff in the } \\
\text { organization }\end{array}$ & 3.715 & 1.122 & 37.538 & 3 & 0.000 \\
\hline Total & & 4.034 & 3.08 & & \\
\hline
\end{tabular}

*significant at P-value less than 0.05 .

Table 8 shows that the effectiveness of using IT in recruitment in the healthcare organization items were significant in each case, where p-value for each item was less than 0.05 and the total mean was 19.75 by SD (3.34).

$>$ In the table, point no (4) gets the highest value Mean \pm SD (4.031 \pm 0.988$)$.

$>$ And point no (5) gets the lowest value with Mean \pm SD (3.715 \pm 1.122$)$.

The percentage of agreement regarding effectiveness indicates that use of IT has an important role in improving effectiveness in the recruitment system and that technically advanced people can provide an effective healthcare 
system, with a total mean value of 20.17 and SD as 3.08. The previous study produced a similar result, suggesting that IT has an important role to play in the healthcare system (Kumar et al., 2013). Hence, the statement is justified.

Table 9. The Responses Regarding the Recruitment Process

\begin{tabular}{|c|c|c|c|c|c|c|}
\hline \multirow{2}{*}{ NO } & \multirow{2}{*}{ Statement } & \multirow{2}{*}{ Mean } & \multirow{2}{*}{ SD } & \multicolumn{3}{|c|}{ Chi-square } \\
\hline & & & & $\mathrm{X}^{2}$ & DF & P-value \\
\hline 1 & $\begin{array}{l}\text { Implementing IT in the recruitment system can provide competitive } \\
\text { advantage in the system }\end{array}$ & 4.108 & 0.874 & 100.615 & 4 & 0.000 \\
\hline 2 & $\begin{array}{l}\text { Present trends in IT development allow qualified aspirants to present } \\
\text { their skills and qualifications in IT platforms }\end{array}$ & 4.077 & 0.886 & 109.462 & 4 & 0.000 \\
\hline 3 & $\begin{array}{l}\text { Advertisements on social media and through email are the most } \\
\text { effective ways to recruit in the healthcare organization }\end{array}$ & 3.908 & 0.849 & 46.923 & 4 & 0.000 \\
\hline 4 & $\begin{array}{l}\text { IT platforms can be helpful in improving the screening, interviewing, } \\
\text { assessment, induction and selection processes }\end{array}$ & 4.038 & 0.839 & 120.154 & 4 & 0.000 \\
\hline 5 & $\begin{array}{l}\text { Use of IT platforms can be helpful in bringing advantages over } \\
\text { traditional recruitment systems }\end{array}$ & 4.038 & 0.884 & 42.123 & 4 & 0.000 \\
\hline Total & & 33.98 & 3.45 & & & \\
\hline
\end{tabular}

*significant at P-value less than 0.05 .

Table 9 shows that every effect of IT on recruitment items in healthcare organizations were significant, where the p-value for each item was less than 0.05 and the total mean was 20.17 by SD (3.08).

$>$ In this table, point no (1) gets the highest value with Mean $\pm \mathrm{SD}(4.108 \pm 0.874)$.

$>$ And point no (3) gets the lowest value with Mean \pm SD (3.908 \pm 0.849$)$.

The significant P-value suggests the effectiveness of IT in healthcare organizations. The previous study's results suggested that there are also some issues in deploying IT in healthcare organizations (Free et al., 2013). However, present trends in IT development allow qualified aspirants to present their skills and qualifications in IT platforms and that advertisement on social media and through email are the most effective ways of recruiting staff in healthcare organizations, which clearly indicates the effectiveness of IT in healthcare organizations.

Table 10. The Multiple Regressions between the Dependent and Independent Variables

\begin{tabular}{|c|c|c|c|c|c|c|c|c|}
\hline \multirow[t]{2}{*}{ Regression } & \multicolumn{2}{|c|}{$\begin{array}{l}\text { Unstandardized } \\
\text { Coefficients }\end{array}$} & \multirow{2}{*}{$\begin{array}{l}\text { Standardized } \\
\text { Coefficients } \\
\text { Beta }\end{array}$} & \multicolumn{2}{|l|}{ ANOVA } & \multicolumn{2}{|l|}{ T-test } & \multirow[t]{2}{*}{$\mathbf{R}^{2}$} \\
\hline & B & Std. Error & & $\mathbf{F}$ & P-value & $t$ & Sig. & \\
\hline (Constant) & 4.851 & 1.437 & & \multirow{5}{*}{35.023} & \multirow{5}{*}{0.000} & 3.376 & 0.001 & \multirow{5}{*}{$52.80 \%$} \\
\hline $\begin{array}{l}\text { The outcome of using IT in recruitment } \\
\text { in the healthcare organization }\end{array}$ & 0.019 & 0.075 & 0.020 & & & 0.259 & 0.796 & \\
\hline $\begin{array}{l}\text { The quality of using IT in recruitment } \\
\text { in the healthcare organization }\end{array}$ & 0.010 & 0.069 & 0.012 & & & 0.145 & 0.885 & \\
\hline $\begin{array}{l}\text { The effect of using IT in recruitment on } \\
\text { communication in the healthcare } \\
\text { organization }\end{array}$ & 0.336 & 0.068 & 0.376 & & & 4.952 & 0.000 & \\
\hline $\begin{array}{l}\text { The effectiveness of using IT in } \\
\text { recruitment in the healthcare } \\
\text { organization }\end{array}$ & 0.407 & 0.072 & 0.441 & & & 5.688 & 0.000 & \\
\hline
\end{tabular}

Dependent Variable: The effect of IT on recruitment in the healthcare organization

*significant at P-value less than 0.05 . 
Table 10 shows that there is a significant model detailing the effect of IT on recruitment in the healthcare organization, the 'Dependent Variable': the outcome of using IT in recruitment in the healthcare organization; the quality of using IT in recruitment in the healthcare organization; the effect of using IT in recruitment in healthcare on communication; and the effectiveness of using IT in recruitment in the healthcare organization, where $\mathrm{F}=35.023$ and P-value $<0.001$ are less than 0.05 with the coefficient of determination $52.80 \%$. The effect of using IT in recruitment in healthcare on communication and the effectiveness of using IT on recruitment in the healthcare organization explain the change to the dependent variable with the percentage $52.8 \%$ and found that the variable outcome of using IT in recruitment in the healthcare organization and the variable the quality of using IT in recruitment in the healthcare organization have no effect, where the value of significance is greater than 0.05 , respectively 0.796 and 0.885 .

Table 11. The value of mean and SD and chi squared for each variable

\begin{tabular}{|c|c|c|c|c|c|c|}
\hline Variables & Mean & SD & Rank & $\mathbf{X}^{2}$ & DF & P-Value \\
\hline $\begin{array}{l}\text { The outcome of using IT on recruitment in the healthcare } \\
\text { organization }\end{array}$ & 4.05 & 3.2 & 1 & 93.800 & 2 & $<0.001 *$ \\
\hline $\begin{array}{l}\text { The quality of using IT in recruitment in the healthcare } \\
\text { organization }\end{array}$ & 3.97 & 3.59 & 4 & 107.185 & 2 & $<0.001 *$ \\
\hline $\begin{array}{l}\text { The effect of using IT in recruitment on communication in the } \\
\text { healthcare organization }\end{array}$ & 3.98 & 3.45 & 3 & 122.092 & 2 & $<0.001 *$ \\
\hline $\begin{array}{l}\text { The effectiveness of using IT on recruitment in the healthcare } \\
\text { organization }\end{array}$ & 4.034 & .34 & 5 & 100.815 & 2 & $<0.001 *$ \\
\hline The effect of IT on recruitment in the healthcare organization & Depe & $\pi$ & & & & \\
\hline
\end{tabular}

This table shows that the independent variable (the outcome of using IT in recruitment in the healthcare organization) gets the highest value, with a Mean \pm SD (20.25 \pm 3.2$)$. That indicates that there is a very strong relationship between the outcome and the effect of using IT in the healthcare recruitment system. Also, it clarifies the relationship between the dependent variable and the independent variables and shows that there is a strong relationship between them. That means there will be a great impact if healthcare organizations apply this system internally.

The advancement in the IT industry has helped in maintaining job allocation to candidates. This research depicts the effect of IT on recruitment in the healthcare industry. The HRM work done in organizations has an expanding important accentuation alongside the significance of the HRM arrangement, and business techniques are very much recognized. Indeed, powerful HRM is the key requisite to keep in mind for meeting the demand of service users for qualified workers.

\section{Conclusions and Recommendations}

As the research is based on the impact of using IT in the healthcare recruitment process, four variables have been taken into account: effectiveness, quality, outcome and communication. Accordingly, we have four hypotheses we want to discuss in relation to our analysis.

- The results show that using information technology will be very useful in the recruitment process because it will provide a better outcome than traditional methods.

- Also, they show that there will be improvement in the quality of recruitment when information technology is used in the recruitment process.

- We have found that there will be a small improvement in communication when IT is used in the recruitment processes instead of the traditional way.

- Finally, the results show that using IT in the recruitment process will be much more effective than the traditional way.

In order to overcome the issues faced while implementing information technology and its application in the healthcare recruitment process, the following points need to be considered.

- As outcome is one of the major components in the healthcare industry recruitment system, the applications for providing care must not vary between institutions. 
- In order to improve quality in the healthcare recruitment process, it is necessary to implement IT applications in the proper way. For instance, those applications that have security issues and may lead to data leakage of candidates must be avoided.

- Using social media could be useful for enhancing communication in the healthcare recruitment process.

- The government has an important role to play in setting up standards for organizations. Adhering to these standards will be helpful in ensuring the effectiveness of the system.

\section{Competing Interests Statement}

All authors declare that they have no conflict of interest.

\section{References}

Arcade, J., Godet, M., Meunier, F., \& Roubelat, F. (2009). Structural Analysis with the MICMAC Method \& Actors' Strategy with MACTOR Method. Futures Research Methodology (3rd ed.). Futures Research Methodology. The Millennium Project, Washington DC.

Betancourt, J. R., Green, A. R., Carrillo, J. E., \& Owusu Ananeh-Firempong, I. I. (2016). Defining cultural competence: A practical framework for addressing racial/ethnic disparities in health and health care. Public health reports.

Boivin, A., Lehoux, P., Lacombe, R., Burgers, J., \& Grol, R. (2014). Involving patients in setting priorities for healthcare improvement: a cluster randomized trial. Implementation Science, 9(1), 24. https://doi.org/10.1186/1748-5908-9-24

Bonevski, B., Randell, M., Paul, C., Chapman, K., Twyman, L., Bryant, J., \& Hughes, C. (2014). Reaching the hard-to-reach: a systematic review of strategies for improving health and medical research with socially disadvantaged groups. BMC medical research methodology, 14(1), 42. https://doi.org/10.1186/1471-2288-14-42

Bower, P., Brueton, V., Gamble, C., Treweek, S., Smith, C. T., Young, B., \& Williamson, P. (2014). Interventions to improve recruitment and retention in clinical trials: A survey and workshop to assess current practice and future priorities. Trials, 15(1), 399. https://doi.org/10.1186/1745-6215-15-399

Boyce, M. B., Browne, J. P., \& Greenhalgh, J. (2014). The experiences of professionals with using information from patient-reported outcome measures to improve the quality of healthcare: A systematic review of qualitative research. BMJ Qual saf, 23(6), 508-518.

Brynjolfsson, E., \& Hitt, L. M. (2000). Beyond computation: Information technology, organizational transformation and business performance. Journal of Economic perspectives, 14(4), 23-48. https://doi.org/10.1257/jep.14.4.23

Carnes, M., Devine, P. G., Manwell, L. B., Byars-Winston, A., Fine, E., Ford, C. E., \& Palta, M. (2015). Effect of an intervention to break the gender bias habit for faculty at one institution: A cluster randomized, controlled trial. Academic medicine: journal of the Association of American Medical Colleges, 90(2), 221.

Choy, L. T. (2014). The strengths and weaknesses of research methodology: Comparison and complimentary between qualitative and quantitative approaches. IOSR Journal of Humanities and Social Science, 19(4), 99-104. https://doi.org/10.9790/0837-194399104

Close, S., Smaldone, A., Fennoy, I., Reame, N., \& Grey, M. (2013). Using information technology and social networking for recruitment of research participants: Experience from an exploratory study of pediatric Klinefelter syndrome. Journal of medical Internet research, 15(3). https://doi.org/10.2196/jmir.2286

Cresswell, K., \& Sheikh, A. (2013). Organizational issues in the implementation and adoption of health information technology innovations: An interpretative review. International journal of medical informatics, 82(5), e73-e86. https://doi.org/10.1016/j.ijmedinf.2012.10.007

De Silva, M. J., Breuer, E., Lee, L., Asher, L., Chowdhary, N., Lund, C., \& Patel, V. (2014). Theory of Change: a theory-driven approach to enhance the Medical Research Council's framework for complex interventions. Trials, 15(1), 267. https://doi.org/10.1186/1745-6215-15-267

Dranove, D., Forman, C., Goldfarb, A., \& Greenstein, S. (2014). The trillion dollar conundrum: Complementarities and health information technology. American Economic Journal: Economic Policy, 6(4), 239-70. https://doi.org/10.1257/pol.6.4.239

Fischer, S. H., David, D., Crotty, B. H., Dierks, M., \& Safran, C. (2014). Acceptance and use of health information 
technology by community-dwelling elders. International journal of medical informatics, 83(9), 624-635. https://doi.org/10.1016/j.ijmedinf.2014.06.005

Flick, U. (2015). Introducing research methodology: A beginner's guide to doing a research project. Sage.

Free, C., Phillips, G., Watson, L., Galli, L., Felix, L., Edwards, P., . . \& Haines, A. (2013). The effectiveness of mobile-health technologies to improve health care service delivery processes: A systematic review and meta-analysis. PLoS medicine, 10(1), e1001363. https://doi.org/10.1371/journal.pmed.1001363

Frey, C. B., \& Osborne, M. A. (2017). The future of employment: how susceptible are jobs to computerisation?. Technological forecasting and social change, 114, 254-280. https://doi.org/10.1016/j.techfore.2016.08.019

Gale, N. K., Heath, G., Cameron, E., Rashid, S., \& Redwood, S. (2013). Using the framework method for the analysis of qualitative data in multi-disciplinary health research. BMC medical research methodology, 13(1), 117. https://doi.org/10.1186/1471-2288-13-117

Ledford, J. R., \& Gast, D. L. (2014). Single case research methodology: Applications in special education and behavioral sciences. Routledge.

George, S., Duran, N., \& Norris, K. (2014). A systematic review of barriers and facilitators to minority research participation among African Americans, Latinos, Asian Americans, and Pacific Islanders. American journal of public health, 104(2), e16-e31. https://doi.org/10.2105/AJPH.2013.301706

Grant, A., Treweek, S., Dreischulte, T., Foy, R., \& Guthrie, B. (2013). Process evaluations for cluster-randomised trials of complex interventions: A proposed framework for design and reporting. Trials, 14(1), 15. https://doi.org/10.1186/1745-6215-14-15

Humphries, B. (2017). Re-thinking social research: anti-discriminatory approaches in research methodology. Routledge.

Jones, E., Taylor, B., MacArthur, C., Pritchett, R., \& Cummins, C. (2016). The effect of early postnatal discharge from hospital for women and infants: A systematic review protocol. Systematic reviews, 5(1), 24. https://doi.org/10.1186/s13643-016-0193-9

Jones, S. S., Rudin, R. S., Perry, T., \& Shekelle, P. G. (2014). Health information technology: an updated systematic review with a focus on meaningful use. Annals of internal medicine, 160(1), 48-54. https://doi.org/10.7326/M13-1531

Kellermann, A. L., \& Jones, S. S. (2013). What it will take to achieve the as-yet-unfulfilled promises of health information technology. Health affairs, 32(1), 63-68. https://doi.org/10.1377/hlthaff.2012.0693

Kumar, S., Nilsen, W. J., Abernethy, A., Atienza, A., Patrick, K., Pavel, M., ... \& Hedeker, D. (2013). Mobile health technology evaluation: the mHealth evidence workshop. American journal of preventive medicine, 45(2), 228-236. https://doi.org/10.1016/j.amepre.2013.03.017

Mackey, A., \& Gass, S. M. (2015). Second language research: Methodology and design. Routledge.

Nunn, A. J., Rusen, I. D., Van Deun, A., Torrea, G., Phillips, P. P., Chiang, C. Y., ... \& Meredith, S. K. (2014). Evaluation of a standardized treatment regimen of anti-tuberculosis drugs for patients with multi-drug-resistant tuberculosis (STREAM): Study protocol for a randomized controlled trial. Trials, 15(1), 353. https://doi.org/10.1186/1745-6215-15-353

Or, C. K., \& Tao, D. (2014). Does the use of consumer health information technology improve outcomes in the patient self-management of diabetes? A meta-analysis and narrative review of randomized controlled trials. International journal of medical informatics, 83(5), 320-329. https://doi.org/10.1016/j.ijmedinf.2014.01.009

Parker, V., Giles, M., Lantry, G., \& McMillan, M. (2014). New graduate nurses' experiences in their first year of practice. Nurse Education Today, 34(1), 150-156. https://doi.org/10.1016/j.nedt.2012.07.003

Riggins, F. J., \& Wamba, S. F. (2015, January). Research directions on the adoption, usage, and impact of the internet of things through the use of big data analytics. In System Sciences (HICSS), 2015 48th Hawaii International Conference on (pp. 1531-1540). IEEE. https://doi.org/10.1109/HICSS.2015.186

Rivers, D., August, E. M., Sehovic, I., Green, B. L., \& Quinn, G. P. (2013). A systematic review of the factors influencing African Americans' participation in cancer clinical trials. Contemporary clinical trials, 35(2), 13-32. https://doi.org/10.1016/j.cct.2013.03.007

Smith, J. A. (2015). Qualitative psychology: A practical guide to research methods. Sage. 
Stephenson, J., Patel, D., Barrett, G., Howden, B., Copas, A., Ojukwu, O., \& Shawe, J. (2014). How do women prepare for pregnancy? Preconception experiences of women attending antenatal services and views of health professionals. PLoS One, 9(7), e103085. https://doi.org/10.1371/journal.pone.0103085

Sudlow, C., Gallacher, J., Allen, N., Beral, V., Burton, P., Danesh, J., ... \& Liu, B. (2015). UK biobank: an open access resource for identifying the causes of a wide range of complex diseases of middle and old age. PLoS medicine, 12(3), e1001779. https://doi.org/10.1371/journal.pmed.1001779

Tarone, E. E., Gass, S. M., \& Cohen, A. D. (2013). Research methodology in second-language acquisition. Routledge: Abingdon.

Treweek, S., Lockhart, P., Pitkethly, M., Cook, J. A., Kjeldstrøm, M., Johansen, M., \& Jones, R. (2013). Methods to improve recruitment to randomised controlled trials: Cochrane systematic review and meta-analysis. $B M J$ open, 3(2), e002360. https://doi.org/10.1136/bmjopen-2012-002360

Turan, A. H., \& Palvia, P. C. (2014). Critical information technology issues in Turkish healthcare. Information \& Management, 51(1), 57-68. https://doi.org/10.1016/j.im.2013.09.007

Vaioleti, T. M. (2016). Talanoa research methodology: A developing position on Pacific research. Waikato Journal of Education, 12(1). https://doi.org/10.15663/wje.v12i1.296

Wartella, E., Rideout, V., Montague, H., Beaudoin-Ryan, L., \& Lauricella, A. (2016). Teens, health and technology: A national survey. Media and communication, 4(3), 13-23. https://doi.org/10.17645/mac.v4i3.515

Wiek, A., \& Lang, D. J. (2016). Transformational sustainability research methodology. In Sustainability Science (pp. 31-41). Springer, Dordrecht.

\section{Copyrights}

Copyright for this article is retained by the author(s), with first publication rights granted to the journal.

This is an open-access article distributed under the terms and conditions of the Creative Commons Attribution license (http://creativecommons.org/licenses/by/4.0/). 